\title{
Neuropeptide Degradation Produces Functional Inactivation in the Crustacean Nervous System
}

\author{
Melissa J. Coleman,, ${ }^{1, a}$ Paul H. Konstant,, ${ }^{1, b}$ Barry S. Rothman, ${ }^{2}$ and Michael P. Nusbaum \\ ${ }^{1}$ Neurobiology Research Center and Department of Physiology and Biophysics, University of Alabama at Birmingham, \\ Birmingham, Alabama 35294-0021 and '2Department of Biology, San Francisco State University, San Francisco, California \\ 94132
}

The pentapeptide proctolin (Proct.; Arg-Tyr-Leu-Pro-Thr) is a modulatory transmitter found throughout the crustacean nervous system. No information is available in this system, however, as to how the actions of this peptide are terminated. To study this issue in the crab Cancer borealis, we incubated exogenous proctolin $\left(10^{-5} \mathrm{M}\right)$ with either the thoracic ganglion (TG) or with conditioned saline (CS) that had been preincubated with the TG. We removed aliquots at standard time points for analysis by reverse-phase highperformance liquid chromatography (HPLC). We found that over time the proctolin peak became progressively smaller, while three novel peaks appeared and increased in size. Comigration experiments using HPLC indicated that the major novel peak was Proct. [2-5] (Tyr-Leu-Pro-Thr), while one of the two minor peaks was Proct. [3-5] (Leu-Pro-Thr). The other minor peak appeared to be Proct. [1-2] (Arg-Tyr), based on similar HPLC retention time to synthetic Proct. [1-2]. The reduction in the proctolin peak and the increase in the Proct. [2-5] peak was prevented by co-incubation of proctolin with any one of several aminopeptidase inhibitors $\left(10^{-4} \mathrm{M}\right)$. Proct. [1-2] and Proct. [3-5] appeared to result from a diaminopeptidase-mediated cleavage of proctolin. We tested whether $\boldsymbol{N}$-terminal cleavage functionally inactivated proctolin by coapplying proctolin $\left(10^{-8} \mathrm{M}\right.$ ) and individual aminopeptidase inhibitors $\left(10^{-5} \mathrm{M}\right)$ to the isolated stomatogastric ganglion (STG). We found that these inhibitors significantly enhanced the proctolin excitation of the pyloric rhythm. Furthermore, application of synthetic Proct. [2-5] to the STG had no effect unless high concentrations $\left(>10^{-6} \mathrm{M}\right)$ were used, and neither Proct. [1-2] nor Proct. [3-5] $\left(10^{-4} \mathrm{M}\right)$ influenced the pyloric rhythm. Our results indicate that proctolin is enzymatically degraded and thereby biologically inactivated in the crab nervous system, primarily by extracellularly located aminopeptidase activity.

\footnotetext{
Received Jan. 19, 1994; revised Mar. 28, 1994; accepted Apr. 13, 1994.

We thank James M. Weimann for providing us with the synthetic proctolin fragments and Rebecca M. Johnston for assisting with statistical analysis. We also thank John Jellies, Brian Norris, and Dvora Konstant for reading earlier versions of the manuscript. This work was supported by BNS-8909613 and NS29436 (M.P.N.), and the Human Frontiers Science Program.

Correspondence should be addressed to Dr. Michael P. Nusbaum, Department of Neuroscience, University of Pennsylvania School of Medicine, 215 Stemmler Hall, Philadelphia, PA 19104-6074.

aPresent address: Department of Neuroscience, University of Pennsylvania School of Medicine, 215 Stemmler Hall, Philadelphia, PA 19104-6074.

'Present address: Department of Physiology and Biophysics, University of Alabama at Birmingham, BHSB-566, Birmingham, AL 35294-0005.

Copyright (C) 1994 Society for Neuroscience $0270-6474 / 94 / 146205-12 \$ 05.00 / 0$
}

[Key words: stomatogastric ganglion, neuromodulation, aminopeptidase, pyloric rhythm, proctolin, neuropeptide, inactivation, Cancer borealis]

Considerable information is available regarding the presence, synthesis, release, and postsynaptic effects of neuropeptide transmitters (White et al., 1985; Polak and Bloom, 1987; Sossin et al., 1989; DeLoof and Schoofs, 1990; Marder and Weimann, 1992). Less is known regarding the postrelease fate of these peptides, and how that fate influences synaptic transmission. Thus far, it has been shown that intact neuropeptides can diffuse relatively long distances from their release sites (Jan and Jan, 1982; Mayeri et al., 1985), or can be enzymatically cleaved in the extracellular space (McKelvy and Blumberg, 1986; Isaac, 1987, 1988; Turner, 1987; Molineaux et al., 1988; Rose et al., 1988; Squire et al., 1991).

In some systems, extracellular cleavage functionally inactivates the neuropeptide (Turner et al., 1985; Hall and Lloyd, 1990; Owens et al., 1992). This inactivation limits the duration and distance over which the peptide influences its targets (Sigvardt et al., 1986). Sometimes, however, enzymatic cleavage either activates or enhances the physiological effects of the peptide (Turner et al., 1985; Thorsett and Wyvratt, 1987; Owens et al., 1992). While some information is available regarding how neuropeptide inactivation influences peptidergic effects at both the cellular (Sigvardt et al., 1986; Owens et al., 1992) and the behavioral level (Turner et al., 1985; Sullivan et al., 1988; Hall and Lloyd, 1990), little is known about the role played by neuropeptide inactivation in sculpting peptidergic modulation of neural network activity.

One well-studied model system for neuropeptide actions on rhythmically active networks is the crustacean stomatogastric nervous system (STNS; Harris-Warrick et al., 1992b; Marder and Weimann, 1992; Weimann et al., 1993). One particularly well-characterized rhythmic motor pattern in this system is the pyloric rhythm, generated by a neural network in the stomatogastric ganglion (STG; Selverston and Moulins, 1987; HarrisWarrick et al., 1992a). The pyloric rhythm is influenced by many different modulatory transmitters, including at least six different neuropeptides (Harris-Warrick et al., 1992b; Marder and Weimann, 1992). Among the best-characterized neuropeptides in the STNS is the pentapeptide proctolin (Proct.; Arg-Tyr-LeuPro-Thr; Marder et al., 1986), which is also found throughout the crustacean CNS (Schwarz et al., 1984; Siwicki and Bishop, 1986). Exogenously applied proctolin causes a dose-dependent excitation of the pyloric rhythm (Marder et al., 1986; Hooper 
and Marder, 1987; Nusbaum and Marder, 1989a,b; Golowasch and Marder, 1992). Within the STNS, proctolin is found in the STG neuropil, in several fibers entering the STG, and in somata in the neighboring commissural (CoGs) and esophageal (OG) ganglia. In the crab Cancer borealis there appear to be only three pairs of proctolin-containing neurons that innervate the STG (Coleman et al., 1992). This includes the paired modulatory proctolin neuron (MPN; Nusbaum and Marder, 1989a,b) and the paired modulatory commissural neuron 1 (MCN1; Christie et al., 1993). Both of these neurons excite the pyloric rhythm.

In this article we examine the fate of exogenously applied proctolin in the nervous system of the crab Cancer borealis. We have found, in biochemical experiments using the relatively large thoracic ganglion (TG), that proctolin is enzymatically degraded primarily by an aminopeptidase (AP) inhibitor-scnsitive process. In complementary electrophysiological experiments, AP inhibitors enhanced the excitatory effects of proctolin on the pyloric rhythm, suggesting that AP activity terminates the proctolin effects in the STG.

Portions of this work were published previously in abstract form (Coleman et al., 1991).

\section{Materials and Methods}

Animals. Cancer borealis were obtained from Neptune Seafood \& Lobster Co. (Boston, MA). Crabs were maintained in refrigerated $\left(10-12^{\circ} \mathrm{C}\right.$ ), aerated aquaria with filtered, circulating artificial seawater. Data were obtained from 72 male crabs weighing between 300 and $800 \mathrm{gm}$.

Solutions. C. borealis physiological saline contained (mmol/liter) $\mathrm{NaCl}$, $440 ; \mathrm{KCl}, 11 ; \mathrm{MgCl}_{2}, 26 ; \mathrm{CaCl}_{2}, 13$; Trizma base, 10 ; and maleic acid, 5 (pH 7.4-7.5). Proctolin and the AP inhibitors amastatin, bestatin, epiamastatin, and puromycin were obtained from Sigma Chemical Co (St. Louis, MO). The AP inhibitors arphamenine B and actinonin were obtained from Peninsula Labs (Belmont, CA). Proct. [2-5] (Tyr-LeuPro-Thr) and Proct. [3-5] (Leu-Pro-Thr) were provided by Dr. James M. Weimann (Department of Biology, Brandeis University), and were synthesized using the procedure for peptide synthesis described in Weimann (1992). Proct. [1-2] (Arg-Tyr) and additional Proct. [3-5] were synthesized by Research Genetics, Inc. (Huntsville, AL). All peptides and peptidase inhibitors were stored either as frozen or lyophilized aliquots of stock solution $\left(10^{-2} \mathrm{M}\right.$ or $\left.10^{-3} \mathrm{M}\right)$ that were diluted to the working concentration in saline immediately before they were used.

Ganglionic incubations. Because a large source of neural tissue was necessary to cleave amounts of proctolin large enough to be detected by absorbance at $206 \mathrm{~nm}$, we used the TG in these experiments. After each dissection, the sheathed TG was pinned to a Sylgard (Dow Corning)coated petri dish and preincubated for at least $30 \mathrm{~min}$ in $3 \mathrm{ml}$ saline. Following several rinses, the $T G$ was then incubated with either (1) saline, (2) saline plus Proct. or Proct. [2-5] (Peptide; $10^{-5} \mathbf{M}$ ), or (3) saline plus peptide $\left(10^{-5} \mathbf{M}\right)$ and peptidase inhibitor $\left(10^{-4} \mathrm{M}\right)$. Each TG incubation was maintained for at least $2 \mathrm{hr}\left(11-15^{\circ} \mathrm{C}\right)$ and $220 \mu \mathrm{l}$ aliquots were removed at $T=1,60$, and $120 \mathrm{~min}$. At $T=0 \mathrm{~min}$, the aliquot contained $2.2 \times 10^{-9} \mathrm{~mol}$ of proctolin. Aliquots immediately received $25 \mu \mathrm{l}$ of $\mathrm{HCl}(1.0 \mathrm{M})$ to inactivate enzymatic activity and were then analyzed by reverse-phase high-performance liquid chromatography (HPLC; see below).

Conditioned saline incubations. Incubations of TG to generate conditioned saline (CS) involved a 30-60 min preincubation with saline, which was replaced with fresh saline $(3 \mathrm{ml})$ for a subsequent $2 \mathrm{hr}$ incubation. This CS was then removed and incubated with the same test solutions described above for TG incubations. All incubations of CS aliquots were performed at $13^{\circ} \mathrm{C}$. Each $\mathrm{CS}$ aliquot was a $700 \mu$ l solution of $\mathrm{CS}(560 \mu \mathrm{l})$ and peptide $\left(10^{-4} \mathrm{M}, 70 \mu \mathrm{l}\right)$ plus either peptidase inhibitor $\left(10^{-3} \mathrm{M}\right)$ or saline $(70 \mu \mathrm{l})$. Final concentrations in each aliquot were $10^{-5}$ $M$ peptide and $10^{-4} \mathrm{M}$ inhibitor (when present). From each aliquot, HPLC samples $(220 \mu \mathrm{l})$ were removed at $T=1,60$, and $120 \mathrm{~min}$, and immediately inactivated by adding $\mathrm{HCl}(1.0 \mathrm{M}, 25 \mu \mathrm{l})$.

$H P L C$. All HPLC analyses were performed using a Rabbit HPX Dual Pump Delivery System with a Dynamic Mixer (Rainin) controlled by a Macintosh SE computer using Dynamax HPLC METHOD MANAGER (version 1.3, Rainin). Sample volumes $(200 \mu \mathrm{l})$ contained $180 \mu \mathrm{l}$ of CS solution plus $20 \mu \mathrm{l}$ of $\mathrm{HCl}$. These samples were analyzed with a Vydac $\mathrm{C}_{18} \mathrm{HPLC}$ analytical column $(0.46 \times 25 \mathrm{~cm}, 300 \AA$ pore size) to which was fitted a Vydac $C_{18}$ guard column and a precolumn filter. Samples were analyzed with $0.1 \%$ trifluoroacetic acid (TFA, pH 2; Aldrich) using a linear gradient of acetonitrile $\left(\mathrm{CH}_{3} \mathrm{CN}\right)$ of $0.2-39 \%$ in $13 \mathrm{~min}(3 \%$ / $\mathrm{min}$ ), at a flow rate of $1.0 \mathrm{ml} / \mathrm{min}$. Peaks were detected at $206 \mathrm{~nm}$ using a Knauer variable wavelength UV detector that was controlled by the METHOD MANAGER software. Control injections were made of synthetic peptide and peptidase inhibitors to verify retention time and to approximate the amount of material producing each peak of interest. Detection threshold for proctolin was approximately $2 \times 10^{-12} \mathrm{~mol}$.

In comigration experiments, material corresponding to peaks of interest was collected during the linear gradient using a Dynamax FC-2 fraction collector (Rainin). Purified samples were dried (SpeedVac Concentrator, Savant) and resuspended in HPLC solution A $\left(99.7 \% \mathrm{H}_{2} \mathrm{O}\right.$, $0.2 \% \mathrm{CH}_{3} \mathrm{CN}$, and $0.1 \%$ TFA). These samples were analyzed by HPLC using the same $\mathrm{C}_{18}$ column and solvents, but under isocratic conditions. The isocractic condition for Proct. [2-5] was $18 \% \mathrm{CH}_{3} \mathrm{CN}$, while for Proct. [3-5] it was $14 \% \mathrm{CH}_{3} \mathrm{CN}$. Each resuspended fraction was halved and the following injections were made to examine each peak of interest: (1) half of the collected peak alone, (2) an approximately equivalent amount of the putative synthetic analog, and (3) a mixture containing the other half of the collected peak and an approximately equal amount of the synthetic analog. To confirm sample identity and purity, after isocratic elution, each peak of interest was analyzed also using the original linear gradient. As a final test of sample purity, the Proct. [2-5] peak was collected again, dried, and resuspended for HPLC analysis under isocratic conditions using a second solvent system with triethylamine (TF.A; $\mathrm{pH} 4.5$; Pierce, Inc.) rather than TFA as the counter ion. With this solvent system, Proct. [2-5] was assayed at $13 \% \mathrm{CH}_{3} \mathrm{HN}$.

HPLC data analysis. All chromatograms were stored for analysis using Dynamax METHOD MANAGER software. The peak arcas for the four peaks of interest - proctolin and the three degradation products-were entered into spreadsheets for further analysis using LoTUs 1-2-3, and then were imported into sigmaplot (version 4.1) for graphic representation. In most cases, data were normalized by representing each peak of interest as a percentage of the summed peak area of all four peaks. However, this analysis was complicated by the fact that three of the peptidase inhibitors used for these studies shared retention times with one or another of the four peaks of interest. Thus, arphamenine B had the same retention time as Proct. [3-5], puromycin the same as Proct. [2-5], and epiamastatin the same as proctolin on the TFA linear gradient. Therefore, some data are also represented as the absolute peak area for each peak of interest. All background peaks with the same retention time as Proct. and the Proct. fragments were subtracted from the peaks of interest beforc analysis and graphic representation. Background peaks were identified as those peaks that were present, with invariant size at all time points, in CS alone aliquots.

Electrophysiology. Electrophysiological experiments were performed on the isolated STNS, which includes the CoGs, OG, and STG, plus their connecting and motor nerves (Fig. 1). The nervous system was pinned down in a Sylgard-coated petri dish, and was superfused continuously with chilled $\left(10-14^{\circ} \mathrm{C}\right)$ physiological saline at a rate of $7-12$ $\mathrm{ml} / \mathrm{min}$. Impulse activity from the CoGs to the STG was blocked by applying isotonic sucrose $\left(7.5 \times 10^{-1} \mathrm{M}\right)$ to a Vaseline well surrounding each desheathed $\mathrm{CoG}$ (Fig. 1). The STG was superfused separately from the OG and all nerves by surrounding the STG with a Vaseline well that held approximately $0.5 \mathrm{ml}$ saline (Fig. 1). Bath volume was approximately $10 \mathrm{ml}$.

The activity of the pyloric motor pattern produced by the STG was monitored continuously by extracellular recordings from identified STG motor nerves (Nusbaum and Marder, 1989a). Extracellular recordings were made using stainless steel wire electrodes that were pressed into the Sylgard alongside individual motor nerves and isolated from the bath by Vaseline.

To examine the effects of coapplication of proctolin and peptidase inhibitor to the STG, saline superfusion in the STG compartment was stopped, and the saline was first replaced with $500 \mu$ l of either saline alone or peptidase inhibitor $\left(10^{-5} \mathbf{M}\right)$ dissolved in saline, and then incubated for $10 \mathrm{~min}$ (incubation 1). Saline alone was then replaced by either saline alone or proctolin $\left(10^{-8} \mathrm{M}\right.$ or $\left.10^{-7} \mathrm{M}\right)$ dissolved in saline $(500 \mu \mathrm{l})$ and again incubated for $10 \mathrm{~min}$ (incubation 2). Similarly, peptidase inhibitor saline was replaced by a saline solution $(500 \mu \mathrm{l})$ containing the same peptidase inhibitor $\left(10^{-5} \mathrm{M}\right)$ plus proctolin $\left(10^{-8} \mathrm{M}\right)$, and incubated for $10 \mathrm{~min}$ (incubation 2). After the second incubation, 
saline superfusion was resumed for $45 \mathrm{~min}$. During test incubations, the temperature in the STG compartment never increased by more than $3^{\circ} \mathrm{C}$ relative to the temperature in the outer compartment or that occurring during saline superfusion of the STG compartment.

Electrophysiology data analysis. Data were analyzed during the final minute of each application. We characterized how proctolin influenced the pyloric motor pattern by monitoring the pyloric cycle frequency and the number of spikes per burst in the lateral pyloric (LP) motor neuron. Cycle frequency was calculated as the reciprocal of the duration from the first spike in a pyloric dilator (PD) neuron burst to the first spike in the next PD neuron burst. Each analyzed segment is an average of either the cycle frequency or the number of LP spikes per burst over 10 consecutive cycles. In some experiments $(N=5)$, proctolin $\left(10^{-7} \mathrm{M}\right)$ caused little $(<0.1 \mathrm{~Hz})$ or no increase in pyloric cycle frequency. We did not include the results from these experiments in our analysis of changes in cycle frequency during application of different peptidase inhibitors. All data were entered into SIGMAPLor for graphic representation.

Statistics. All statistical analyses were performed using GBSTAT (version 3.0). Statistical significance was determined by using either Student's $t$ test or, for three or more test conditions, analysis of variance (ANOVA). Tukey's $t$ test was used for post hoc multiple comparisons of ANOVA, with a critical level of $\alpha=0.05$. All data are presented as mean \pm standard deviation (SD). Statistical analyses of the data in Tables 2-5 were performed by comparing the difference between incubation 2 and incubation 1 for each experimental condition relative to this difference for the control condition $\left(10^{-8} \mathrm{M}\right.$ or $10^{-7} \mathrm{M}$ proctolin in saline without any inhibitors, as indicated in each table).

The proctolin data from Tables 2 and 3, and those from Tables 4 and 5 , were obtained from separate experiments. In each case, the proctolin data were obtained from the same preparations as were the other data in the same table.

\section{Results}

\section{Proctolin degradation}

Incubations of proctolin with the TG, followed by HPLC analysis of aliquots of the incubate at 1,60, and 120 min time points, revealed that the amount of proctolin present in the incubate diminished over the course of $2 \mathrm{hr}(N=4$; Fig. $2 A)$. In contrast, when the same amount of proctolin was incubated under the same conditions with saline alone, the size of the HPLC-detected proctolin peak remained constant over a $2 \mathrm{hr}$ period (not shown). In parallel with the reduction in the size of the proctolin peak during TG incubations there appeared three novel HPLC-detected peaks, called putative proctolin fragments 1-3 (PPF-1, PPF-2, PPF-3), which increased in size with incubation time (Fig. 24). Thus, at $T=1 \mathrm{~min}$, nearly all $(97 \%)$ of the analyzed peak area resulted from proctolin. At $T=120 \mathrm{~min}$, only $82 \%$ of this area was due to the proctolin peak and the remaining $18 \%$ resulted from the PPF peaks. The concomitant decrease in the proctolin peak and increase in three novel peaks suggested that proctolin was being degraded by the TG and that the novel peaks were the resulting proctolin degradation products (see below).

PPF-1, the largest of the three novel HPLC-detected peaks, had a retention time on the linear gradient of $13.3 \mathrm{~min}$, and thus eluted immediately before the proctolin peak, which had a retention time of $13.7 \mathrm{~min}$ (Fig. 2). PPF-2 and PPF-3 had retention times of $11.9 \mathrm{~min}$ and $10.6 \mathrm{~min}$, respectively (Fig. 2). Generally, no PPF-2 or PPF-3 was detected in the $T=1 \mathrm{~min}$ aliquot. In contrast, the $T=1 \mathrm{~min}$ aliquot routinely showed a small but discernable peak at the PPF-1 retention time (Fig. 2). This peak, however, resulted from background absorbance as it was also present in control (CS alone) HPLC injections (Fig. $2 B$, top trace).

We examined the extent to which the proctolin-degrading activity was released into the saline. To this end, we produced

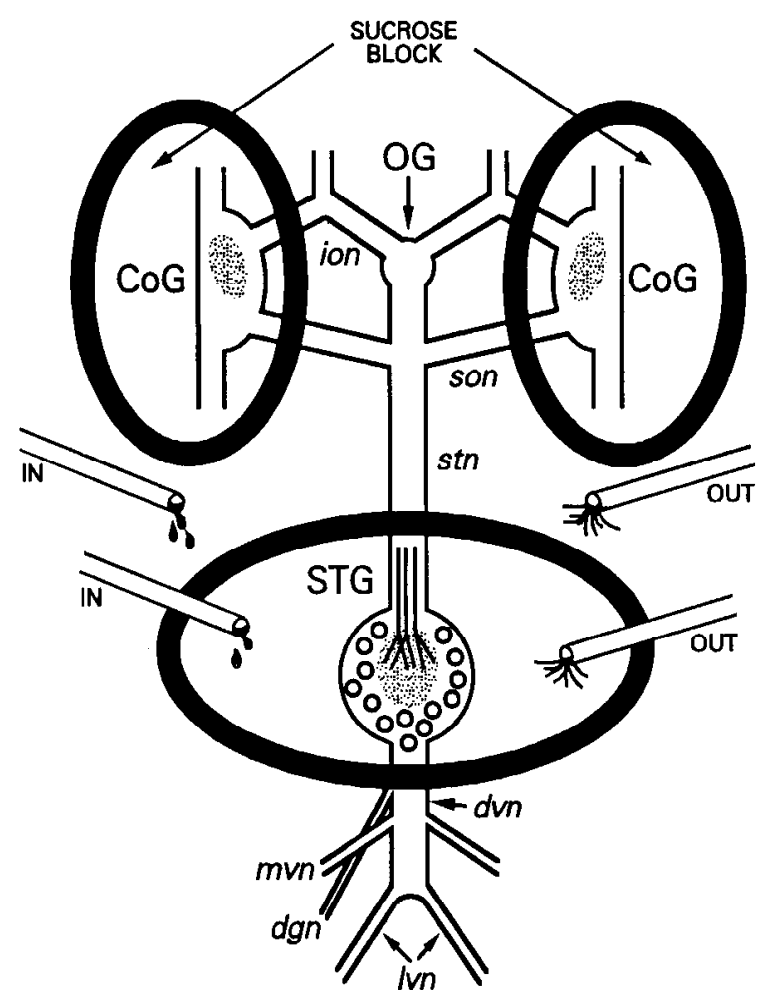

Figure 1. Schematic diagram of the stomatogastric nervous system (STNS) of the crab Cancer borealis. The paired commissural ganglia ( $C o G$ ) were surrounded by Vaseline wells (heavy lines) and the saline inside the wells was replaced with isotonic sucrose $\left(7.5 \times 10^{-1} \mathrm{M}\right)$. The stomatogastric ganglion $(S T G)$ was surrounded by a separate Vaseline well. The STG was superfused separately from the remainder of the STNS. Shaded region in each ganglion represents the neuropil. In the STG, the neuropil is surround by the neuronal somata. Three lines entering the neuropil represent the axons of neurons innervating the STG from CoGs and OG. $d g n$, dorsal gastric nerve; $d v n$, dorsal ventricular nerve; ion, inferior esophageal nerve; $l v n$, lateral ventricular nerve; $m v n$, medial ventricular nerve; $O G$, esophageal ganglion; son, superior esophageal nerve; st $n$, stomatogastric nerve.

conditioned saline from the TG, after which this CS was incubated with proctolin (see Materials and Methods; $N=20$ ). Similar to its incubation with the TG, the proctolin peak diminished over time with CS incubation and the same three novel peaks were the only nonproctolin peaks to change with time (Fig. $2 B$ ). Surprisingly, the CS was as effective in degrading proctolin as was incubating the peptide directly with the TG itself $(p>0.05$ Table 1$)$. As shown by the aggregate data $(N=$ 20 ) in Figure 3 , the amount of each PPF produced in CS at $T=60 \mathrm{~min}$ and $120 \mathrm{~min}$ was significantly greater than that produced at $T=1 \mathrm{~min}$. At all time points, the size of the PPF-1 peak was greater than either of the other two novel peaks. Concomitantly, there was a significant reduction in the proctolin peak at these later time points. Thus, the amount of the initial proctolin aliquot $(1.8 \pm 0.15 \mathrm{nmol})$ remaining at $T=60 \mathrm{~min}$ was $1.66 \pm 0.12 \mathrm{nmol}$, while there was $1.55 \pm 0.14 \mathrm{nmol} \mathrm{re}$ maining at $T=120 \mathrm{~min}$. For these experiments, during the 120 min incubations, the proctolin degradation rate was approximately $0.19 \mathrm{nmol} / \mathrm{liter} / \mathrm{sec}$

The ability of the TG to produce conditioned saline that effectively degraded proctolin was not limited to the first $2 \mathrm{hr}$ incubation. In three experiments, three successive conditioned 


\section{B. CS + Proctolin}

\section{Control (CS alone)}

A. $T G+$ Proctolin
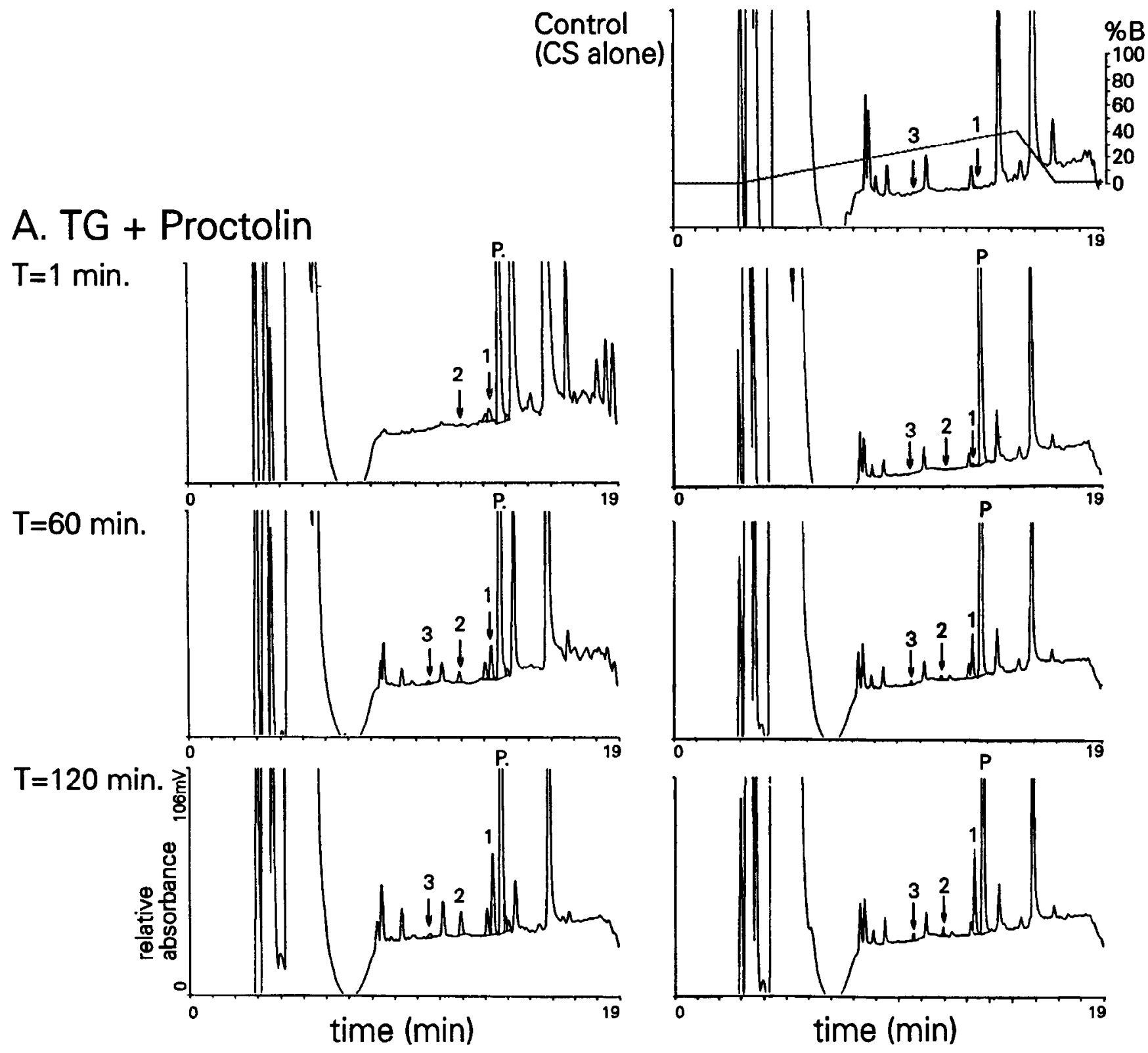

\begin{tabular}{|c|c|c|c|c|}
\hline \multicolumn{5}{|c|}{ \% Total Peak Area } \\
\hline & peak & peak & peak & peak $P$. \\
\hline $\begin{array}{l}T=1 \mathrm{~min} . \\
T=60 \mathrm{~min} . \\
T=120 \mathrm{~min}\end{array}$ & $\begin{array}{l}0.0 \\
0.4 \\
0.8\end{array}$ & $\begin{array}{l}0.2 \\
1.6 \\
3.9\end{array}$ & $\begin{array}{r}2.6 \\
5.6 \\
13.0\end{array}$ & $\begin{array}{l}97.2 \\
92.4 \\
82.3\end{array}$ \\
\hline
\end{tabular}

\begin{tabular}{|c|c|c|c|c|}
\hline \multicolumn{5}{|c|}{$\%$ Total Peak Area } \\
\hline & \multicolumn{4}{|c|}{ peak 3 peak 2 peak 1 peak $P$} \\
\hline $\begin{array}{l}T=1 \mathrm{~min} . \\
T=60 \mathrm{~min} . \\
T=120 \mathrm{~min} .\end{array}$ & $\begin{array}{l}0.1 \\
0.6 \\
1.0\end{array}$ & $\begin{array}{l}0.0 \\
0.5 \\
1.2\end{array}$ & $\begin{array}{r}0.5 \\
5.9 \\
11.6\end{array}$ & $\begin{array}{l}99.5 \\
93.1 \\
86.3\end{array}$ \\
\hline
\end{tabular}

Figure 2. Proctolin $\left(10^{-5} \mathrm{M}\right)$ degradation resulting from incubation with the TG $(A)$ and conditioned saline $(C S$, $B)$. In each case, HPLC chromatograms show proctolin degradation at different time points. With increasing incubation time, the putative proctolin fragment (PPF) peaks increased in size. All unlabeled peaks are background peaks that are unrelated to proctolin. Peaks were analyzed at $206 \mathrm{~nm}$. Peak 3, PPF-3 (RY); peak 2, PPF-2 (LPT); peak 1, PPF-1 (YLPT); peak P., proctolin (RYLPT = Arg-Tyr-Leu-Pro-Thr).

salines were produced, each one involving a $2 \mathrm{hr}$ incubation with the same TG (Fig. 4). In each of these experiments, we found that CS 3 was essentially as effective as CS 1 in reducing the size of the proctolin peak and increasing the size of the PPF peaks on HPLC.

\section{Identification of proctolin degradation products}

We reasoned, by comparing the above results with those of earlier studies of proctolin degradation in insect neural tissue (Quistad et al., 1984; Isaac, 1987), that the PPFs were likely to 


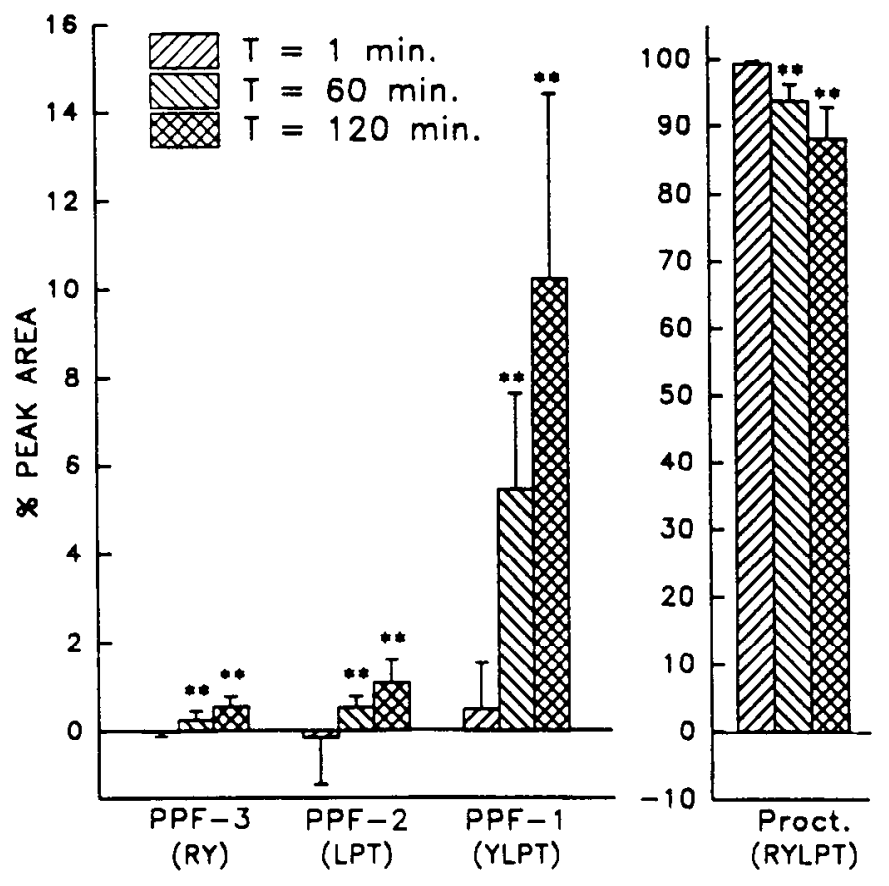

Figure 3. Mean proctolin and PPF peak areas with increasing incubation time in CS $(N=20)$. With increasing incubation time, the percentage of the total peak area due to proctolin decreased while it increased for the PPFs. Note the different scale on the ordinate for the PPF peaks and the proctolin peak. Data are plotted as percentage of total peak area, with $100 \%$ equal to the sum of the peak areas of PPF3, PPF-2, PPF-1, and Proct.; ${ }^{* *}, p<0.01$ compared to $T=1 \mathrm{~min}$ (ANOVA), for each peak of interest. Abbreviations are the same as in Figure 2.

be Proct. [2-5] (PPF-1), Proct. [3-5] (PPF-2), and Proct. [1-2] (PPF-3). To determine if this was indeed the case, we performed HPLC comigration experiments and compared the retention times of purified PPF-1 and PPF-2 with synthetic analogs (see Materials and Methods). It was difficult to collect and purify sufficient PPF-3 for comigrations, so we compared the HPLC retention time of PPF-3 and synthetic Proct. [1-2] (see below). Purified PPF-1 did indeed comigrate with synthetic Proct. [25], both under isocratic conditions $(N=5$; Fig. $5 A)$ and with a linear gradient (data not shown). Similarly, PPF-2 comigrated with synthetic Proct. [3-5] under isocratic conditions $(N=5$; Fig. 5B). To verify further the identity of PPF-1, we used a second solvent system that used TEA in place of TFA as the counter-ion (see Materials and Methods). Under these conditions, PPF-1 again comigrated with Proct [2-5] (not shown; $n$ $=3$ ). Recovery of PPF-2 was insufficient for accurate analysis with the TEA solvent system. In parallel HPLC injections, using the TFA linear gradient, synthetic Proct. [1-2] had the same retention time as PPF-3.

Proct. [1-2] and Proct. [3-5] could have been coproduced by a single diaminopeptidase (DAP)-mediated cleavage. Proct. [35], however, could also have been produced by AP cleavage of Proct. [2-5]. To study this latter possibility, we incubated synthetic Proct. [2-5] $\left(7 \times 10^{-9} \mathrm{~mol}\right)$ both with the TG and with $\mathrm{CS}$, using the same protocols and HPLC analysis that were used for proctolin incubations. Both TG $(N=3$; data not shown) and CS $(N=4$; Fig. 6$)$ degraded Proct. [2-5] and produced Proct. [3-5]. After $2 \mathrm{hr}$ CS incubations, $94.3 \pm 2.2 \%$ of the total peak area was Proct. [2-5] (Fig. 6), as compared with approximately $88 \%$ being due to the proctolin peak (Table 1) after comparable

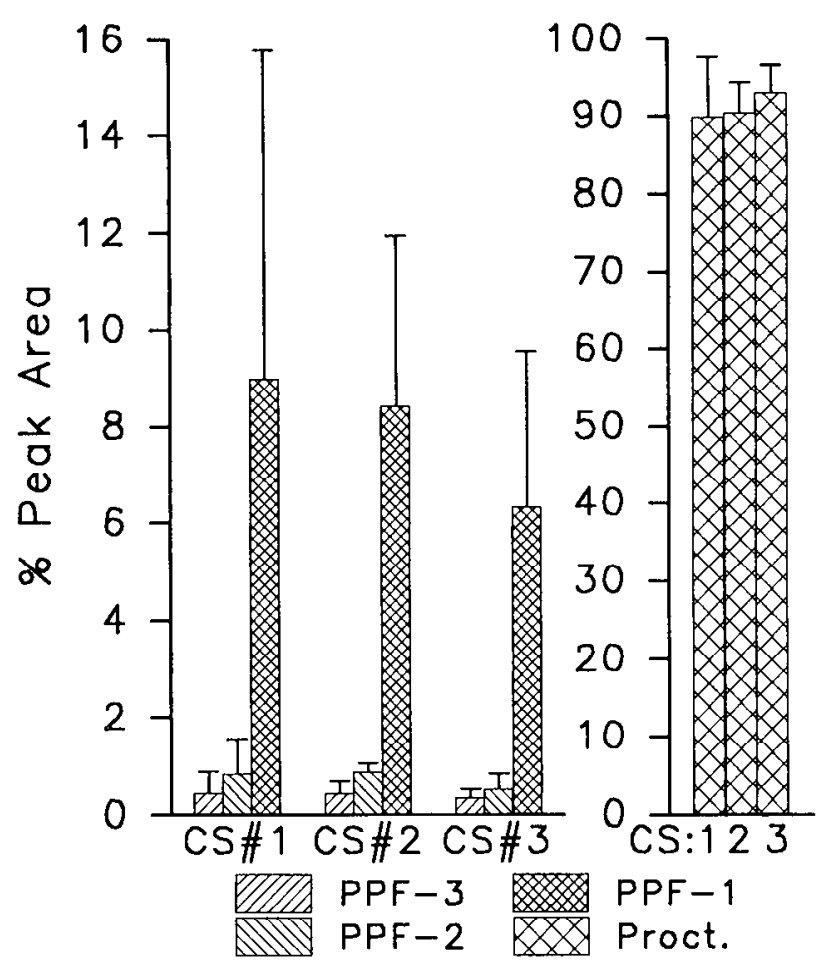

Figure 4. Proctolin $\left(10^{-5} \mathrm{M}\right)$ degradation by sequentially generated conditioned salines from the TG, assayed after incubations of $120 \mathrm{~min}$. Data are plotted as the percentage of the total peak area of the proctolin and PPF peaks. All three conditioned salines were from normal Cancer saline. $N=3 ; p>0.05$ (ANOVA), for comparisons of corresponding peaks in all three incubations.

proctolin incubations. Thus, after these $2 \mathrm{hr}$ incubations, aliquots contained $1.59 \pm 0.07 \mathrm{nmol}$ of Proct. [2-5], while aliquots at $T=0$ min contained $1.80 \pm 0.19 \mathrm{nmol}$. This resulted in a degradation rate of approximately $0.22 \mathrm{nmol} / \mathrm{liter} / \mathrm{sec}$, which was similar to the proctolin degradation rate $(0.19 \mathrm{nmol} / \mathrm{liter} /$ $\mathrm{sec}$ ). As shown in Figure 6, there were increasing amounts of Proct. [3-5] produced over the course of the $2 \mathrm{hr}$ incubations. Thus, Proct. [3-5] could be produced by serial $N$-terminal cleavage of proctolin. In contrast to the proctolin incubation experiments, no Proct. [1-2] was produced from the Proct. [2-5] incubations.

\section{Aminopeptidase inhibitors diminish proctolin degradation}

Proctolin had been shown to be sensitive to AP activity (Quistad et al., 1984; Isaac, 1987), so we tested the ability of six different AP inhibitors to prevent proctolin degradation by CS. As shown in Figures 7 and 8, each AP inhibitor that we tested was able to prevent at least partially the reduction in the size of the proctolin peak and/or the appearance of one or more of the proctolin fragment peaks. For the inhibitors amastatin, acti-

Table 1. Proctolin degradation during CS incubation versus TG incubation (\% total peak area at $T=120 \mathrm{~min}$ )

\begin{tabular}{lllll} 
& $\begin{array}{l}\text { PPF-3 } \\
\text { (RY) }\end{array}$ & $\begin{array}{l}\text { PPF-2 } \\
\text { (LPT) }\end{array}$ & $\begin{array}{l}\text { PPF-1 } \\
\text { (YLPT) }\end{array}$ & $\begin{array}{l}\text { Proct. } \\
\text { (RYLPT) }\end{array}$ \\
\hline CS $(N=20)$ & $0.6 \pm 0.2$ & $1.1 \pm 0.5$ & $10.2 \pm 4.2$ & $88.1 \pm 4.8$ \\
TG $(N=4)$ & $0.9 \pm 0.2$ & $3.5 \pm 1.4$ & $13.3 \pm 4.9$ & $84.2 \pm 4.2$ \\
\hline
\end{tabular}

$p>0.05$, Student's $t$ test, for comparison of each peak in TG versus CS. 
Figure 5. Comigration of proctolin degradation products and their synthetic analogs: HPLC chromatograms under $\mathrm{CH}_{3} \mathrm{CN}$ isocratic conditions, following collection from $\mathrm{CH}_{3} \mathrm{CN}$ linear gradient using TFA as the counter-ion (see Materials and Methods) for synthetic Proct. [2-5] and PPF-1 $(A)$, and synthetic Proct. [3-5] and PPF-2 $(B)$. $A 1$, Half of synthetic Proct. [2-5] fraction collected from linear gradient. $A 2$, Half of PPF-1 fraction collected from linear gradient following proctolin incubation in CS. A3, Combination of second half of synthetic Proct. [2-5] and second half of PPF-1 from proctolin degradation in CS. BI, Half of synthetic Proct. [3-5] fraction collected from previous TFA linear gradient. $B 2$, Half of PPF-2 fraction collected from previous TFA linear gradient following proctolin incubation in CS. B3, Combination of half of synthetic Proct. [3-5] and PPF-2 fractions. Arrows indicate peaks of interest. Unlabeled peaks are solvent front and background peak.

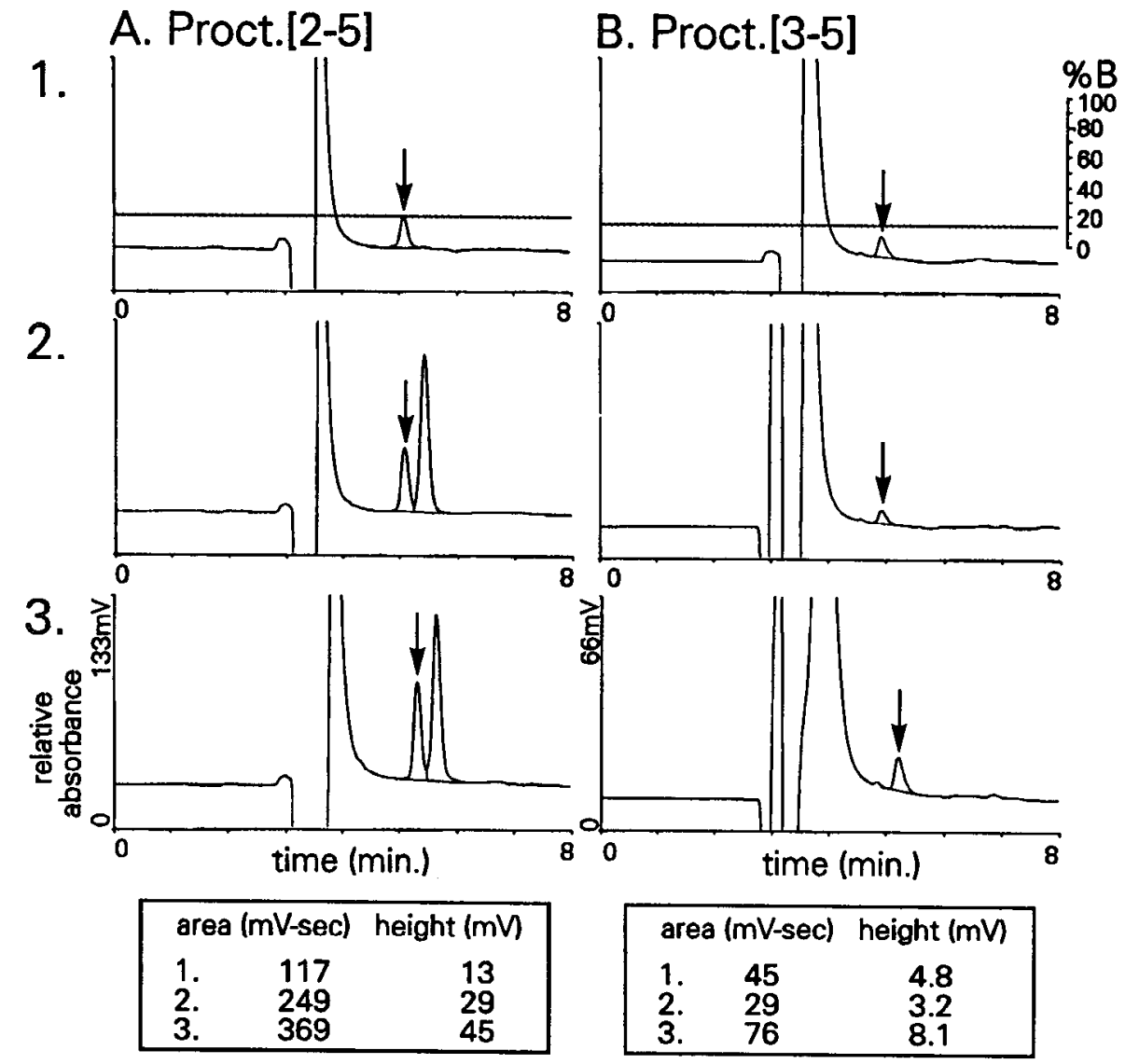

nonin, and bestatin, we quantitatively analyzed the fraction of the initial amount of proctolin that was found in the form of proctolin, Proct. [2-5], Proct. [3-5], and Proct. [1-2] after $2 \mathrm{hr}$ co-incubations of CS with proctolin and each inhibitor (Fig. $8 A$ ). Because of overlap of HPLC retention times with peaks of interest, data for the other three inhibitors could only be analyzed as peak areas (see Materials and Methods; Fig. 8B). When we compared these peaks with those resulting from incubation of proctolin without inhibitor, we found that each of these inhibitors significantly decreased the amount of proctolin degradation (Fig. 8). In terms of the size of either the proctolin peak or that of Proct. [2-5], amastatin and actinonin were equally effective and were more effective than bestatin. For example, after $2 \mathrm{hr}$ incubations, $88 \%$ of the total peak area was proctolin when no inhibitors were present, while $93 \%$ was proctolin when bestatin was also present and $98 \%$ was proctolin when either amastatin or actinonin was present (Fig. $8 A$ ).

Interestingly, the ability of each inhibitor to prevent the appearance of Proct. [2-5] did not necessarily correlate with the ability of that inhibitor to block the appearance of Proct. [3-5] and Proct. [1-2]. Thus, relative to CS alone, only actinonin significantly reduced the amount of both Proct. [3-5] and Proct. [1-2] (Figs. 7, 8). While amastatin also significantly reduced the size of the Proct. [3-5] peak, it did not change the size of the Proct. [1-2] peak relative to CS alone (Figs. 7, 8). Additionally, whereas bestatin and arphamenine had little influence on Proct. [3-5], their presence produced a slight increase in the Proct. [12] peak size (Fig. $8 B$ ). Puromycin did not alter the size of either the Proct. [3-5] or Proct. [1-2] peaks.

Like proctolin degradation, the Proct. [2-5] degradation was also amastatin sensitive. Thus, after $120 \mathrm{~min}$ co-incubations of Proct. [2-5] plus amastatin in CS, the Proct. [2-5] peak was indistinguishable from that of controls (percentage total peak area, $99.1 \pm 0.2 \% ; N=4)$ and only trace amounts $(<1 \%)$ of Proct. [3-5] were detected. In contrast, approximately $6 \%$ of the peak area was represented by the Proct. [3-5] peak after 120 min incubations of Proct. [2-5] with CS alone (Fig. 6). This amastatin-sensitive degradation of Proct. [2-5] presumably accounts for the decrease in the Proct. [3-5] peak that occurred from proctolin incubations in CS plus amastatin. No other inhibitor was tested on Proct. [2-5] degradation.

\section{Proctolin actions are enhanced by aminopeptidase inhibitors}

To test the physiological role of the AP activity identified in our biochemical studies, we examined the ability of the AP inhibitors used in these biochemical studies to influence the modulatory effects of proctolin on the pyloric motor pattern in the stomatogastric ganglion. The experimental setup is illustrated in Figure 1 and is described in the Materials and Methods. We reasoned that if the AP inhibitors effectively prevented proctolin degradation, then they should enhance the proctolin-mediated excitation of the pyloric motor pattern in the STG. To test this hypothesis, we applied each AP inhibitor $\left(10^{-5} \mathbf{M}\right)$ with proctolin $\left(10^{-8} \mathrm{M}\right)$. As predicted, many of these inhibitors did enhance the proctolin excitation of the pyloric motor pattern (Figs. 9, 10; Tables 2, 3: incubation 2 vs 1). In contrast, none of these inhibitors influenced the pyloric motor pattern when applied alone (Tables 2, 3: incubation 1). The enhanced excitation that occurred when these inhibitors were coapplied with proctolin included (1) a faster pyloric motor pattern, and (2) 

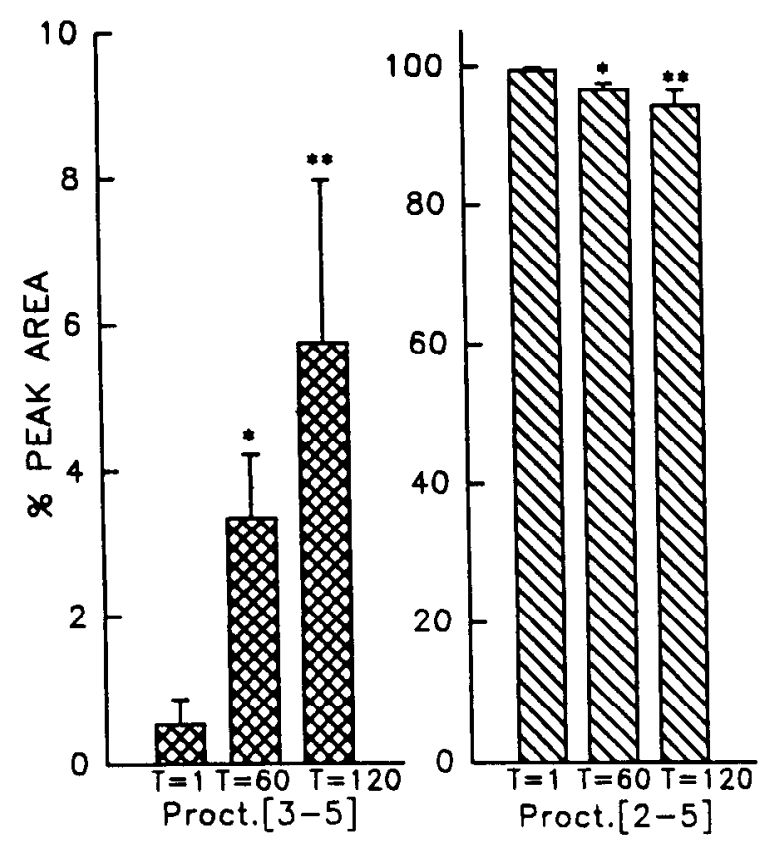

Figure 6. Proct. [2-5] $\left(10^{-5} \mathrm{M}\right)$ is degraded during incubations with CS from the TG. The percentage of the total peak area (Proct. [2-5] plus Proct. [3-5]) due to Proct. [2-5] decreased while that due to Proct. [3-5] increased with increasing incubation time. $N=4 ;{ }^{* *}, p<0.01$; ${ }^{*}, p<0.05$; compared to $T=1 \mathrm{~min}$ (ANOVA) for each peak of interest. Data are plotted as in Figure 3.

more intense impulse bursts in several pyloric neurons. For example, in the experiment shown in Figure 9, bestatin only slightly enhanced the proctolin-mediated excitation of the pyloric rhythm, but amastatin increased this activity such that it was equivalent to that occurring in the presence of a 10 -fold higher concentration of proctolin. Only the peptidase inhibitors amastatin and arphamenine $B$ significantly increased the pyloric cycle frequency relative to proctolin $\left(10^{-8} \mathrm{M}\right)$ alone (Table 2). While the effects of actinonin on cycle frequency appeared to be comparably large, they were only studied in two experiments (Table 2). In contrast, all five inhibitors enhanced the number of LP neuron impulses per burst as compared with proctolin $\left(10^{-8} \mathrm{M}\right)$ alone (Fig. 10, Table 3). Bestatin and arphamenine B, however, were less effective than actinonin, epiamastatin, and amastatin, all of which enhanced the effects of $10^{-8} \mathrm{M}$ proctolin on LP neuron activity such that it was indistinguishable from that resulting from application of $10^{-7} \mathrm{M}$ proctolin (Fig. 10, Table 3).

\section{Physiological actions of proctolin degradation products}

To test whether the observed proctolin cleavages were inactivating the peptide, we studied the effects on the pyloric motor pattern of bath applying each identified proctolin degradation product to the STG. As shown in Figure 11, when we applied Proct. [2-5] in the concentration range where the parent peptide effectively excites the pyloric rhythm $\left(10^{-9} \mathrm{M}\right.$ to $\left.10^{-6} \mathrm{M}\right)$, there was no effect on this motor pattern. However, higher doses of Proct. $[2-5]\left(>10^{-6} \mathbf{M}\right)$ did excite the pyloric rhythm $(n=3-5)$. This effect was moderately strong for applications of $10^{-5} \mathrm{M}$ Proct. [2-5] and it was particularly strong for applications of 5 $\times 10^{-5} \mathrm{M}$ (Fig. 11). These latter effects were indistinguishable from those of lower doses of the parent peptide $\left(10^{-7} \mathrm{M}\right.$ proctolin; Fig. 1, Tables 4, 5). In contrast to the results with Proct.

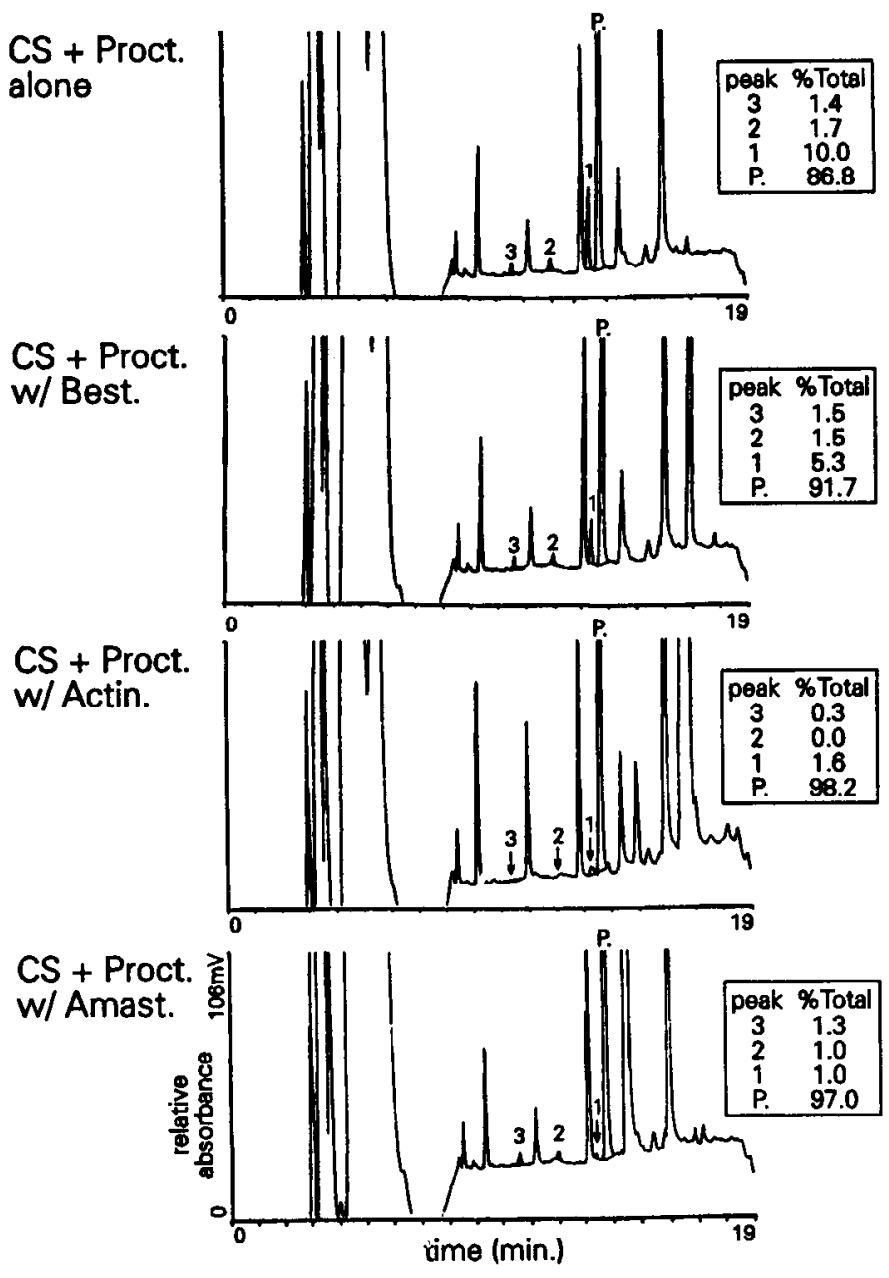

Figure 7. Proctolin degradation in the presence of different aminopeptidase inhibitors: HPLC chromatograms of aliquots of proctolin $\left(10^{-5} \mathrm{M}\right)$ plus or minus aminopeptidase inhibitor $\left(10^{-4} \mathrm{M}\right)$ in $\mathrm{CS}$, after incubation for $120 \mathrm{~min}(T=120 \mathrm{~min})$. The size of the proctolin peak and that of peak $l$ were both reduced with aminopeptidase inhibitors present when compared with CS plus proctolin alone. Additionally, peak 2 was reduced by amastatin and actinonin, while peak 3 was reduced by actinonin. Best., bestatin; Actin., actinonin; Amast., amastatin; Proct., proctolin.

[2-5], bath application of even higher doses $\left(10^{-4} \mathrm{M}\right)$ of Proct. [1-2] and Proct. [3-5] had no effect on the pyloric rhythm ( $N$ $=4$; data not shown).

\section{Discussion}

Proctolin degradation by conditioned saline

In this study we have shown that the pentapeptide proctolin is cleaved by the crab nervous system. This cleavage is mediated primarily by AP activity, although there appears to be some DAP-like activity as well. Surprisingly, we found that saline preincubated with the TG had nearly as much proctolin-cleaving activity as the TG. Thus, nearly all of the proctolin-cleaving activity was probably released into the extracellular space rather than remaining tightly bound to ganglionic membranes.

There are several possible explanations for the generation of proctolin-degrading activity in the CS. For example, this activity might have resulted from exocytosis. Alternatively, the activity might have been tethered to the extracellular surface of ganglionic membranes by a labile linkage that was continually cleaved. Neither of these possibilitics was examined in our experiments. 

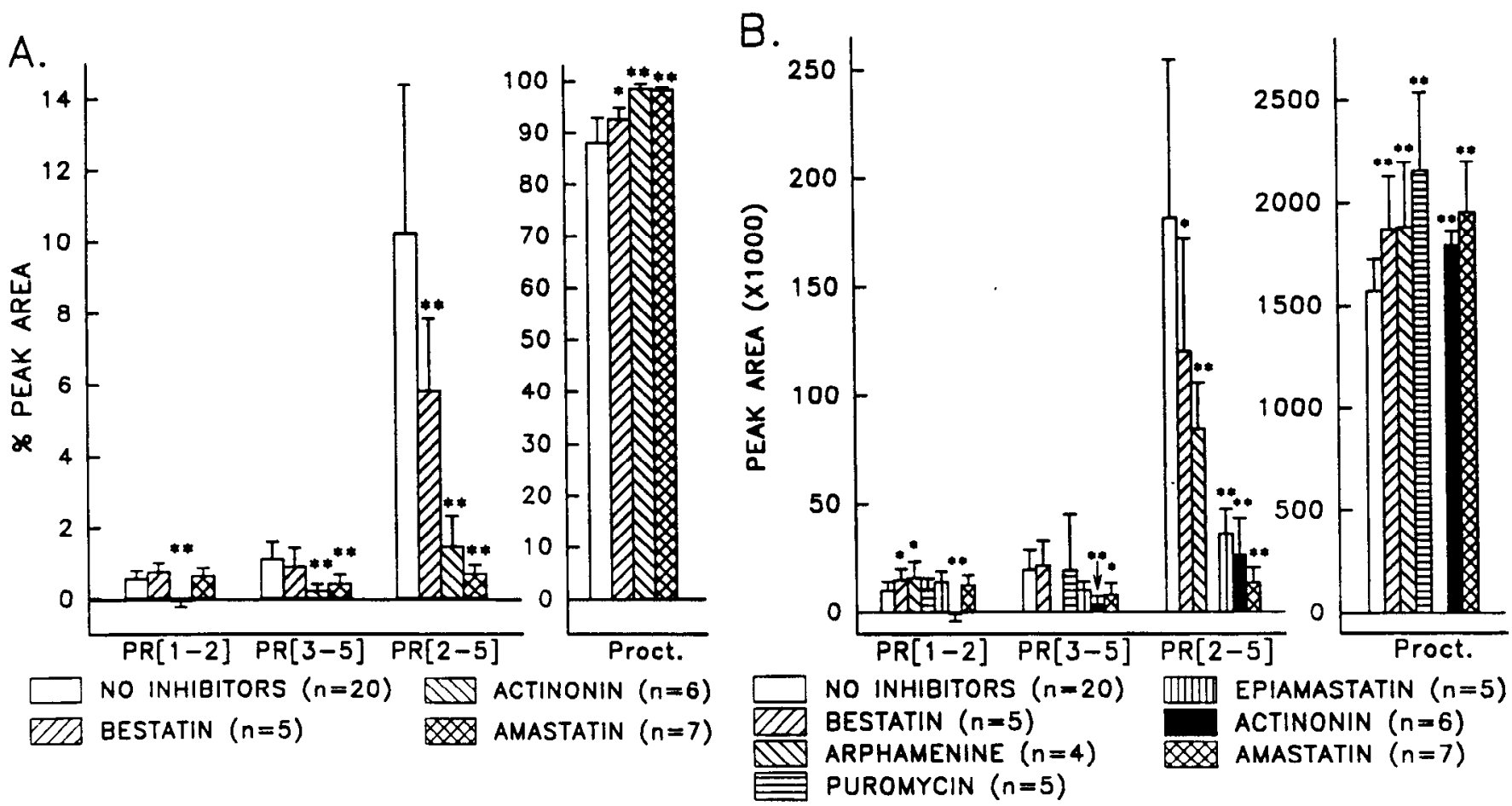

Figure 8. Summary of effectiveness of different aminopeptidase inhibitors on CS-mediated proctolin degradation. $A$, Percentage of total peak area represented by each of the proctolin-related peaks. Data were collected following proctolin incubation $\left(10^{-5} \mathrm{M}\right)$ with $\mathrm{CS}$ plus or minus an aminopeptidase inhibitor $\left(10^{-4} \mathrm{M}\right)$ at $T=120 \mathrm{~min}$. For each condition, data are plotted as the mean peak area for each peak divided by the mean total area for the four proctolin-related peaks. $B$, Mean peak area of proctolin and each proctolin fragment after $\mathrm{CS}$ incubation of proctolin (10 $0^{-5} \mathrm{M}$ ), plus or minus an aminopeptidase inhibitor $\left(10^{-4} \mathrm{M} ; T=120 \mathrm{~min}\right)$. Data for no inhibitors, bestatin, actinonin, and amastatin are replotted from A. Missing bars indicate values for which the inhibitor shared the same retention time as the peak of interest. Overlapping peaks are arphamenine B and Proct. [3-5], puromycin and Proct. [2-5], and epiamastatin and proctolin. Statistical analysis indicates significantly different than CS with no inhibitors within each peak of interest: ${ }^{* *}, p<0.01 ;{ }^{*}, p<0.05$; ANOVA.

However, there is precedence for the latter possibility in that other cell surface enzymes, including acetylcholinesterase, are membrane anchored via a phospholipase C-sensitive, glycosylphosphatidylinositol linkage (Futerman et al., 1985; Haas et al., 1988; Low and Saltiel, 1988). Such a linkage also exists for at least one AP, aminopeptidase P (AP-P; EC 3.4.11.9; Hooper and Turner, 1988).

\section{Multiple proctolin-degrading enzymes?}

Our results are consistent with proctolin cleavage in the crab nervous system being mediated by at least two different enzymes. The major proctolin-degrading activity appears to be an AP, since most of the proctolin cleavage is suppressed by AP inhibitors, and our HPLC comigration experiments indicate that the major AP inhibitor-sensitive degradation product is Proct. [2-5].

The second proctolin-dcgrading activity appears to be a DAP. This conclusion is based primarily on the coappearance of Proct. [1-2] and Proct. [3-5] in proctolin incubations with either CS or TG. While Proct. [3-5] was also produced via serial, AP inhibitor-sensitive cleavages of proctolin, the larger source of Proct. [3-5] generation appeared to be cleavage of the Tyr-Leu bond via DAP activity. This interpretation is supported by the observation that in most of the proctolin co-incubations with AP inhibitors, the same amounts of Proct [3-5] and Proct. [12] were generated as without any inhibitor present, even though Proct. [2-5] production was reduced significantly. The DAP-like activity, however, can only account for about $20 \%$ of the total proctolin degradation, because approximately $80 \%$ of the proctolin degradation is eliminated in the presence of the AP-inhibitor amastatin.

\section{Identity of the proctolin-cleaving peptidases}

Previous workers (McDonald and Barrett, 1986; Turner et al., 1989) have characterized four distinct mammalian APs that show some similarity to the proctolin-cleaving activity that we have described in the crab nervous system. These include leucine AP (LAP; EC 3.4.11.1), aminopeptidase M (AP-M; EC 3.4.11.2), aminopeptidase B (AP-B; EC 3.4.11.6), and aminopeptidase A (AP-A; EC 3.4.11.7). Each of these peptidases exhibits different substrate and inhibitor specificities. Of these enzymes, the likeliest ones to degrade proctolin effectively are LAP, AP-M, and AP-B. Purified mammalian LAP has been shown to cleave proctolin effectively in solution, although the cleavage products were not identified (Brown, 1977; Davis et al., 1989). The preferred substrates for both AP-M and AP-B include peptides, such as proctolin, with an $N$-terminal arginine (McDonald and Barrett, 1986; Turner et al., 1989). Each of these APs, however, has been reported to have an inhibitor-sensitivity profile that is distinct from that of the proctolin-sensitive AP activity seen by us in the crab (Umezawa and Aoyagi, 1983; McDonald and Barrett, 1986). It is, however, possible that the AP activity in our study represents several different enzymes with overlapping inhibitor sensitivities, rather than a single AP. Supporting this possibility is our finding that the crab AP ac- 


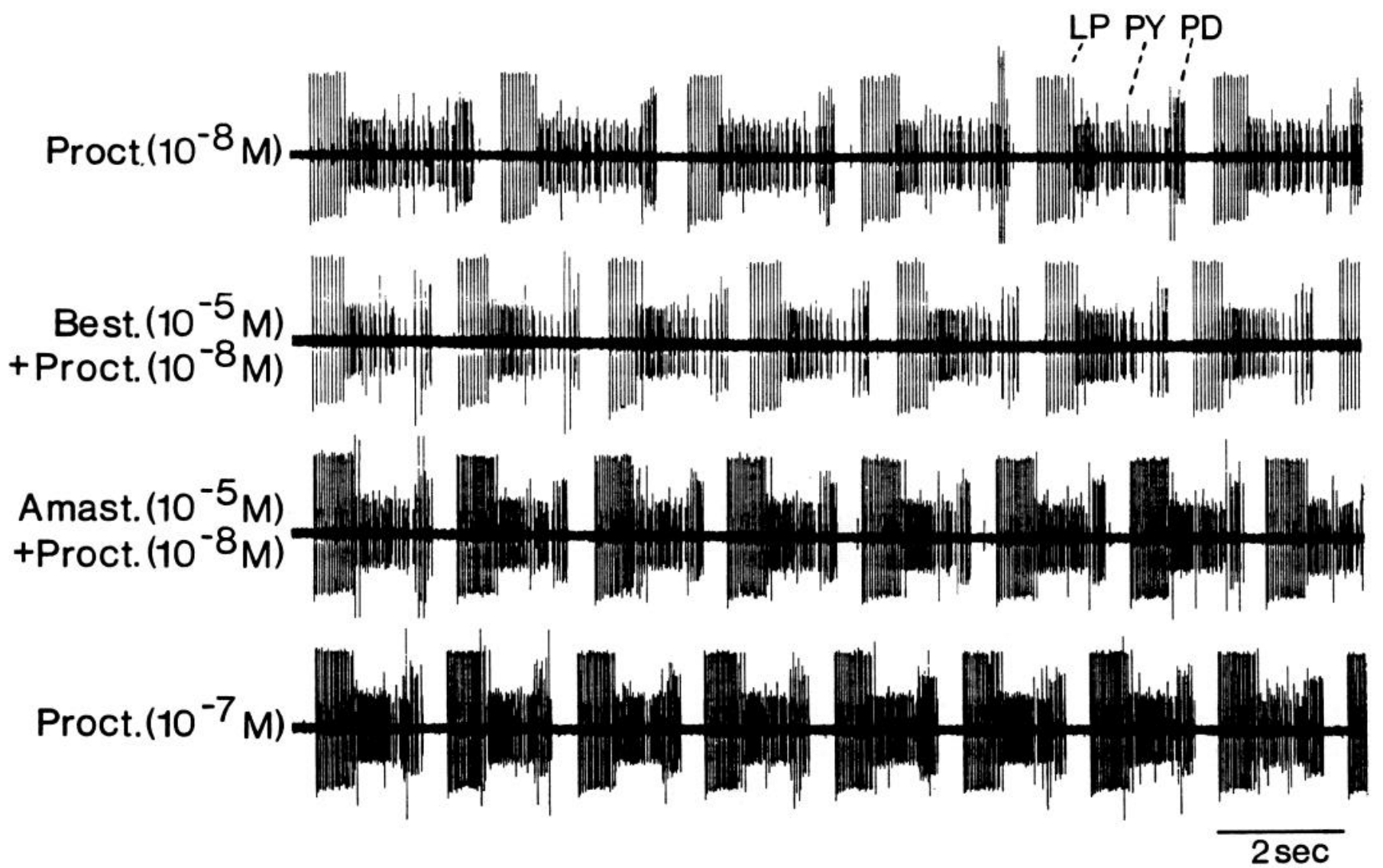

Figure 9. Effects of bath-applied aminopeptidase inhibitors $\left(10^{-5} \mathbf{M}\right)$ on the excitatory effects of proctolin $\left(10^{-8} \mathbf{M}\right)$ on the pyloric motor pattern. Activity of an ongoing pyloric motor pattern from a single experiment is monitored by extracellular recordings of a pyloric motor nerve, the $d v n$ (see Fig. 1). $L P$, lateral pyloric constrictor motor neuron; $P Y$, pyloric constrictor motor neuron; $P D$, pyloric dilator motor neuron.

tivity was approximately equally inhibited by amastatin, actinonin, puromycin, and epiamastatin.

Previous work in the insect nervous system showed that extracellular proctolin is a substrate of AP activity and that its degradation was most effectively inhibited by amastatin (Quis-

Table 2. The effect of aminopeptidase inhibitors on the proctolinmediated excitation of the pyloric rhythm cycle frequency $(\mathrm{Hz})$

\begin{tabular}{llll} 
& $\begin{array}{l}\text { Saline } \\
\text { superfusion }\end{array}$ & Incubation 1 & Incubation 2 \\
\hline Saline $(n=5)$ & $0.45 \pm 0.2$ & $0.47 \pm 0.2$ & $0.46 \pm 0.2 \dagger$ \\
$10^{-8}$ M proctolin $(n=9)$ & $0.46 \pm 0.2$ & $0.47 \pm 0.1$ & $0.54 \pm 0.2 \dagger$ \\
Bestatin $(n=7)$ & $0.39 \pm 0.2$ & $0.44 \pm 0.2$ & $0.50 \pm 0.2 \dagger$ \\
Epiamastatin $(n=5)$ & $0.48 \pm 0.1$ & $0.48 \pm 0.2$ & $0.55 \pm 0.2 \dagger$ \\
Arphamenine B $(n=5)$ & $0.39 \pm 0.1$ & $0.38 \pm 0.2$ & $0.49 \pm 0.2^{*}$ \\
Actinonin $(n=2)$ & $0.54 \pm 0.4$ & $0.63 \pm 0.4$ & $0.72 \pm 0.2$ \\
Amastatin $(n=5)$ & $0.47 \pm 0.1$ & $0.47 \pm 0.1$ & $0.61 \pm 0.1^{*}$ \\
$10^{-7}$ M proctolin $(n=5)$ & $0.42 \pm 0.2$ & $0.45 \pm 0.2$ & $0.66 \pm 0.2^{*}$
\end{tabular}

"Incubation 1" indicates STG incubation with either saline (for saline, $10^{-8} \mathrm{M}$ proctolin, and $10^{-7} \mathrm{M}$ proctolin) or aminopeptidase inhibitor $\left(10^{-5} \mathrm{M}\right.$, for all others). "Incubation 2" indicates STG incubation with incubate 1 plus either saline (for saline), $10^{-7} \mathrm{M}$ proctolin (for $10^{-7} \mathrm{M}$ proctolin), or $10^{-8} \mathrm{M}$ proctolin (for all others). See Materials and Methods for further details.

*Value is significantly different from $10^{-8} \mathrm{M}$ proctolin application: $p<0.05$, Student's $t$ test.

$\dagger$ Value is significantly different from $10^{-7} \mathrm{M}$ proctolin application: $p<0.05$, Student's $t$ test. tad et al., 1984; Isaac, 1987). However, other aspects of the inhibitor profile determined by Isaac (1987) for the proctolincleaving AP activity of insect neural membrane fractions differed from that of the AP activity described in the present study. Proctolin was also degraded by DAP activity in these previous studies, although the particular DAP responsible for this degradation was not identified (Quistad et al., 1984; Isaac, 1987). However, Hui (1988) reported that proctolin is readily cleaved by DAP V. DAP V, purified from rat brain membranes, strongly prefers peptides with an arginine residue at the $\mathrm{N}$-terminus, including proctolin.

\begin{tabular}{|c|c|c|c|}
\hline & $\begin{array}{l}\text { Saline } \\
\text { superfusion }\end{array}$ & Incubation 1 & Incubation 2 \\
\hline Saline $(n=8)$ & $4.4 \pm 1.4$ & $4.4 \pm 1.6$ & $4.3 \pm 1.6 * \dagger$ \\
\hline $10^{-8} \mathrm{M}$ proctolin $(n=12)$ & $4.2 \pm 1.5$ & $4.3 \pm 1.7$ & $6.6 \pm 2.7 \dagger$ \\
\hline Bestatin $(n=8)$ & $5.3 \pm 2.8$ & $5.6 \pm 3.3$ & $9.1 \pm 3.4^{*} \dagger$ \\
\hline Arphamenine B $(n=7)$ & $4.2 \pm 1.6$ & $3.6 \pm 2.0$ & $8.0 \pm 2.5^{*} \dagger$ \\
\hline Actinonin $(n=4)$ & $5.3 \pm 3.4$ & $5.6 \pm 2.6$ & $11.2 \pm 3.2^{*}$ \\
\hline Epiamastatin $(n=5)$ & $4.1 \pm 1.4$ & $4.0 \pm 2.1$ & $9.9 \pm 3.2^{*}$ \\
\hline Amastatin $(n=11)$ & $5.0 \pm 1.5$ & $5.5 \pm 2.0$ & $11.6 \pm 2.9^{*}$ \\
\hline $10^{-7} \mathrm{M}$ proctolin $(n=8)$ & $4.8 \pm 1.9$ & $4.5 \pm 2.1$ & $12.6 \pm 3.5^{*}$ \\
\hline
\end{tabular}

Details are as for Table 2. 


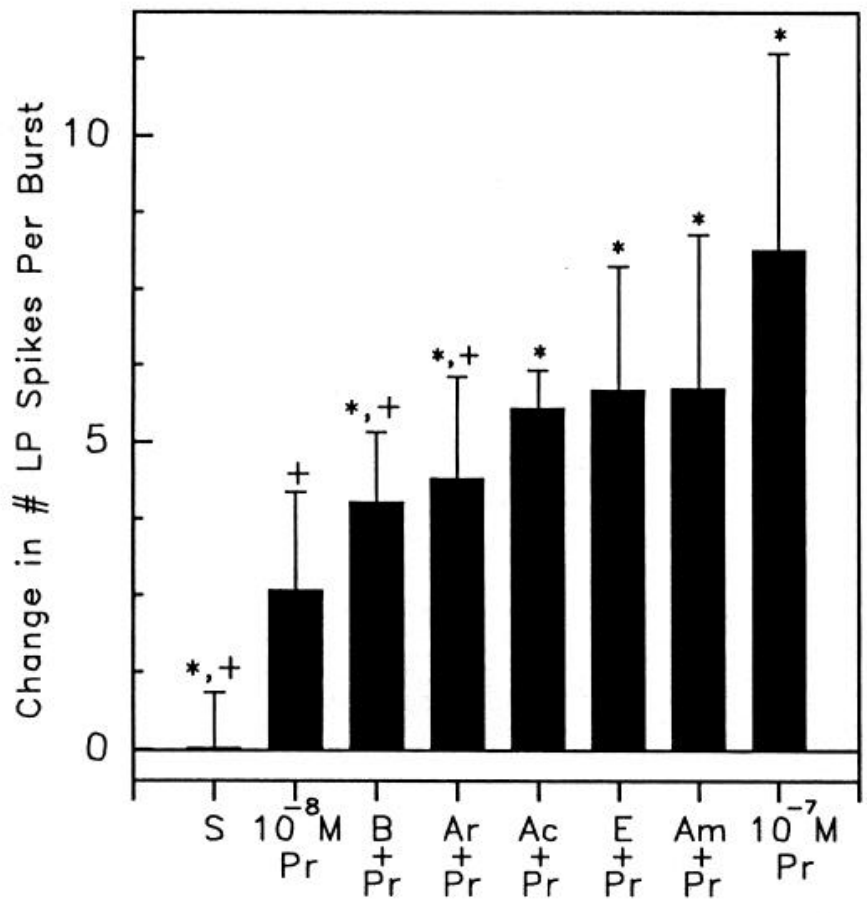

Figure 10. Cumulative results of the influence of different aminopeptidase inhibitors on the proctolin-mediated changes in the number of LP neuron impulses per burst. Data represent the mean difference from application of either saline (saline, $10^{-8} \mathrm{M}$ Proct., $10^{-7} \mathrm{M}$ Proct.) or the relevant inhibitor. Each inhibitor $\left(10^{-5} \mathrm{M}\right)$ was first applied alone, and then immediately coapplied with proctolin $\left(10^{-8} \mathrm{M}\right) . S$, saline $(n=8)$; $10^{-8} M \mathrm{Pr}$, proctolin $(n=12) ; B$, bestatin $(n=8) ; A r$, arphamenine $(n$ $=8) ; A c$, actinonin $(n=4) ; E$, epiamastatin $(n=5) ; A m$, amastatin $(n$ $=10$ ); $10^{-7} \mathrm{M} ; \mathrm{Pr}$, proctolin $(n=8){ }^{*}, p<0.05$ (relative to $10^{-8} \mathrm{M}$ Proct.);,$+ p<0.05$ (relative to $10^{-7}$ м Proct.); Student's $t$ test.

\section{Physiological role of proctolin-cleaving peptidases}

Our results are consistent with there being extracellularly located AP activity within the STG that terminates the neural actions of proctolin. This conclusion is based on the fact that the same AP inhibitors that effectively suppressed proctolin degradation in our biochemical experiments were able to enhance the excitatory effects of bath-applied proctolin in our electrophysiological experiments. Although we analyzed the enzymatic degradation of proctolin using a different ganglion than we used to monitor its electrophysiological effects, the order of effectiveness of the peptidase inhibitors used in both types of experiments was similar.

In addition to the proctolin-degrading activity reported by us to reside within the crab nervous system, there is previously

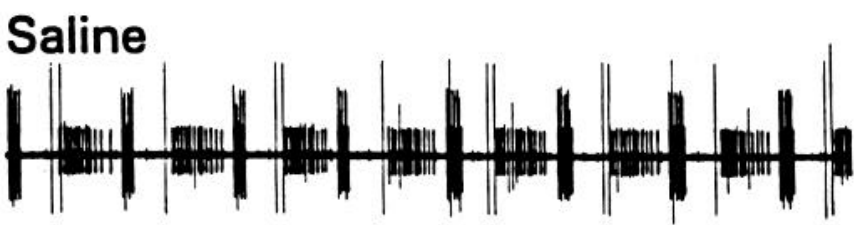

$10^{-6} \mathrm{M}$ Proct.[2-5]

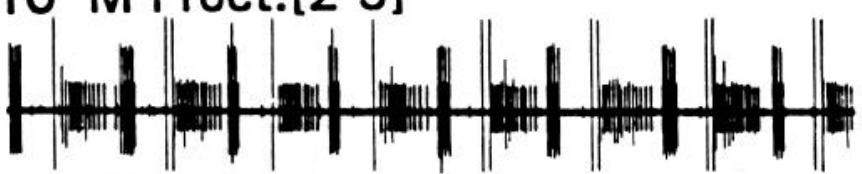

$10^{-5} \mathrm{M}$ Proct.[2-5]

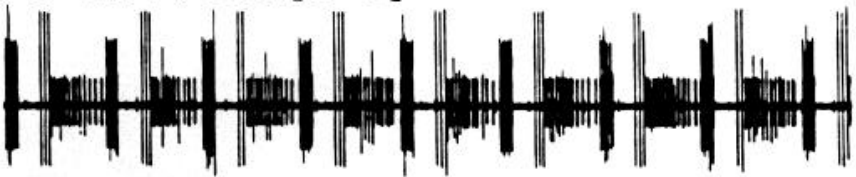

$5 \times 10^{-5} \mathrm{M}$ Proct.[2-5]

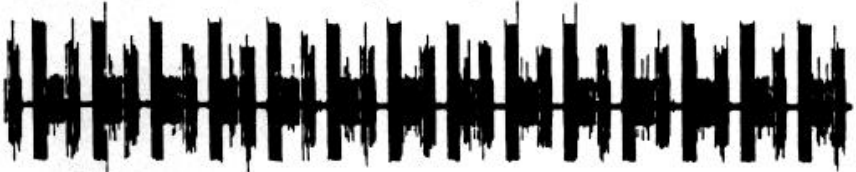

$10^{-7} \mathrm{M}$ Proct.

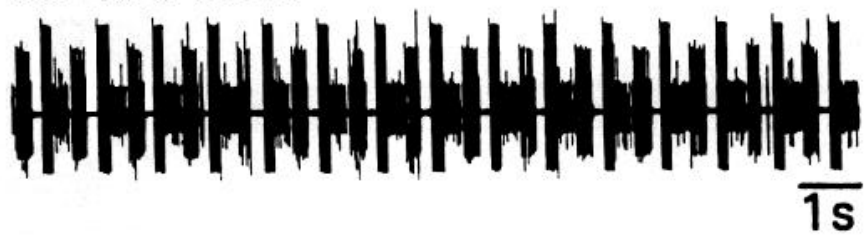

Figure 11. Effects of Proct. [2-5] on the pyloric motor pattern. Bath application of Proct. [2-5] at $<10^{-5} \mathrm{M}$ to the isolated STG did not influence the pyloric motor pattern. However, higher concentrations of Proct. [2-5] $\left(5 \times 10^{-5} \mathrm{M}\right)$ excited the pyloric motor pattern in a manner similar to bath application of proctolin $\left(10^{-7} \mathrm{M}\right)$. Pyloric motor pattern was monitored by an extracellular recording of the $d v n$. All recordings were from the same preparation.

reported proctolin-degrading activity within the crustacean hemolymph. Schwarz et al. (1984) reported that, in preliminary experiments where they injected exogenous proctolin in the hemolymph of the lobster Homarus americanus, proctolin was degraded with a half-life of 6-10 min. Proctolin cleavage also occurs in insect hemolymph (Steele and Starratt, 1985). Because the STG is located within a major artery, any neurally released proctolin that was not degraded by ganglionic enzyme activity would likely be degraded in the hemolymph. Our experiments

Table 4. The effect of Proct. [2-5] on the pyloric cycle frequency (Hz)

\begin{tabular}{llll} 
& Saline superfusion & Incubation 1 & Incubation 2 \\
\hline Saline $(n=6)$ & $0.49 \pm 0.04$ & $0.53 \pm 0.1$ & $0.55 \pm 0.1 \dagger$ \\
$10^{-8} \mathrm{M}$ proctolin $(n=7)$ & $0.59 \pm 0.2$ & $0.58 \pm 0.1$ & $0.63 \pm 0.1 \dagger$ \\
$10^{-7} \mathrm{M}$ proct. [2-5] $(n=3)$ & $0.55 \pm 0.1$ & $0.64 \pm 0.1$ & $0.64 \pm 0.1 \dagger$ \\
$10^{-6} \mathrm{M}$ proct. [2-5] $(n=4)$ & $0.55 \pm 0.2$ & $0.61 \pm 0.2$ & $0.64 \pm 0.1 \dagger$ \\
$10^{-5} \mathrm{M}$ proct. [2-5] $(n=4)$ & $0.47 \pm 0.2$ & $0.56 \pm 0.1$ & $0.65 \pm 0.04$ \\
$5 \times 10^{-5}$ M proct. $[2-5](n=5)$ & $0.56 \pm 0.1$ & $0.61 \pm 0.2$ & $0.79 \pm 0.2^{*}$ \\
$10^{-7} \mathrm{M}$ proctolin $(n=10)$ & $0.53 \pm 0.1$ & $0.61 \pm 0.2$ & $0.76 \pm 0.2^{*}$ \\
\hline
\end{tabular}


Table 5. The effect of Proct. [2-5] on the number of spikes per burst in the LP neuron

\begin{tabular}{lllc} 
& Saline superfusion & Incubation 1 & Incubation 2 \\
\hline Saline $(n=6)$ & $4.3 \pm 1.0$ & $4.4 \pm 0.7$ & $3.8 \pm 0.9 \dagger$ \\
$10^{-8} \mathrm{M}$ proctolin $(n=7)$ & $4.9 \pm 1.9$ & $5.1 \pm 1.7$ & $6.8 \pm 1.8 \dagger$ \\
$10^{-7} \mathrm{M}$ proct. $[2-5](n=3)$ & $3.8 \pm 2.5$ & $3.4 \pm 2.0$ & $3.2 \pm 1.1 \dagger$ \\
$10^{-6} \mathrm{M}$ proct. [2-5] $(n=4)$ & $4.3 \pm 2.8$ & $4.6 \pm 2.5$ & $5.2 \pm 2.8 \dagger$ \\
$10^{-5} \mathrm{M}$ proct. [2-5] $(n=4)$ & $4.6 \pm 3.9$ & $4.4 \pm 3.1$ & $7.2 \pm 3.4 \dagger$ \\
$5 \times 10^{-5} \mathrm{M}$ proct. $[2-5](n=5)$ & $5.7 \pm 2.4$ & $4.5 \pm 2.3$ & $11.8 \pm 1.7^{*}$ \\
$10^{-7} \mathrm{M}$ proctolin $(n=10)$ & $4.3 \pm 2.7$ & $4.6 \pm 2.3$ & $12.9 \pm 3.2^{*}$ \\
\hline
\end{tabular}

Details are as for Table 2.

do not enable us to predict which of these two sources of proctolin-degrading activity would be larger.

We were surprised to find that proctolin was only approximately 500-fold more effective than Proct. [2-5] in exciting the pyloric motor pattern. An earlier study by Starratt and Brown (1979), using a proctolin-sensitive muscle assay, showed that proctolin was $>10^{6} \times$ more effective than Proct. [2-5]. Whether this difference results from different proctolin receptors, differential sensitivities to resident peptidases, or differential access to receptors remains to be determined.

The proctolin degradation reported in the present study may well contribute to the relatively short-lasting excitatory effects of two proctolin-containing neurons, MPN and MCN1, on the pyloric motor pattern in the crab STG (Nusbaum and Marder, 1989a,b; Nusbaum et al., 1992; Christie et al., 1993; Coleman and Nusbaum, 1994). Whereas some modulatory neurons have effects that long outlast their period of impulse activity (HarrisWarrick et al., 1992b), the effects of both MPN and MCN1 subside within seconds after their activity is terminated (Nusbaum and Marder, 1989a,b; Nusbaum et al., 1992). Because the effects of the proctolin neurons on the pyloric rhythm are equivalent to bath application of $10^{-7} \mathrm{M}$ to $10^{-6} \mathrm{M}$ proctolin and threshold for proctolin actions on this system is approximately $10^{-9} \mathrm{M}$ (Marder et al., 1986; Nusbaum and Marder, 1989b), the local concentration of neurally released proctolin probably decreases by $2-3$ orders of magnitude within several seconds or less. Such a rapid decrease in local proctolin concentration would be facilitated by the proctolin-cleaving actions identified in the present study. Finally, since many extracellularly located peptidases cleave more than one neuropeptide (Turner et al., 1985; Turner, 1987), it is possible that the peptidase activities documented in this study also degrade other neurally released peptides in the crustacean nervous system.

\section{References}

Brown BE (1977) Occurrence of proctolin in six orders of insects. J Insect Physiol 23:861-864.

Christie AE, Norris BJ, Coleman MJ, Marder E, Nusbaum MP (1993) Neuropil arborization and transmitter complement of a modulatory projection neuron. Soc Neurosci Abstr 19:931.

Coleman MJ, Nusbaum MP (1994) Functional consequences of compartmentalization of synaptic input. $J$ Neurosci 14: in press.

Coleman MJ, Nusbaum MP, Rothman BS (1991) Proctolin degradation by the crab nervous system. Soc Neurosci Abstr 17:278.

Coleman MJ, Nusbaum MP, Cournil I, Claiborne BJ (1992) Distribution of modulatory inputs to the stomatogastric ganglion of the crab, Cancer borealis. J Comp Neurol 325:581-594.

Davis NT, Velleman SG, Kingan TG, Keshishian H (1989) Identification and distribution of a proctolin-like neuropeptide in the nervous system of the gypsy moth, Lymantria dispar, and in other Lepidoptera. J Comp Neurol 283:71-85.
DeLoof A, Schoofs L (1990) Homologies between the amino acid sequences of some vertebrate peptide hormones and peptides isolated from invertebrate sources. Comp Biochem Physiol 95B:459-468.

Futerman M, Fionini RM, Roth E, Low MG, Silman I (1985) Physiochemical behaviors and structural characteristics of membrane bound acetylcholinesterase from Torpedo: effect of phosphatidylinositol specific phospholipase C. Biochem J 226:369-377.

Golowasch J, Marder E (1992) Proctolin activates an inward current whose voltage dependence is modified by extracellular $\mathrm{Ca}^{2+}$. J Neurosci 12:810-817.

Haas R, Marshall TC, Rosenberry TL (1988) Drosophila acetylcholinesterase: demonstration of a glycoinositol phospholipid anchor and an endogenous proteolytic cleavage. Biochemistry 27:6453-6457.

Hall JD, Lloyd PE (1990) Involvement of pedal peptide in locomotion in Aplysia: modulation of foot muscle contractions. J Neurobiol 21: 858-868.

Harris-Warrick RM, Marder E, Selverston AI, Moulins M, eds (1992a) Dynamic biological networks: the stomatogastric nervous system. Boston: MIT Press.

Harris-Warrick RM, Nagy F, Nusbaum MP (1992b) Neuromodulation of stomatogastric networks by identified neurons and neurotransmitters. In: Dynamic biological networks: the stomatogastric nervous system (Harris-Warrick RM, Marder E, Selverston AI, Moulins M, eds), pp 87-137. Boston: MIT Press.

Hooper SL, Marder E (1987) Modulation of the lobster pyloric rhythm by the peptide proctolin. J Neurosci 7:2097-2112.

Hooper NM, Turner AJ (1988) Ectoenzymes of the kidney microvillar membrane: aminopeptidase $\mathbf{P}$ is anchored by a glycosyl-phosphatidylinositol moiety. FEBS Lett 229:340-344.

Hui K-S (1988) A novel dipeptidyl aminopeptidase in rat brain membranes. J Biol Chem 263:6613-6618.

Isaac RE (1987) Proctolin degradation by membrane peptidases from nervous tissue of the desert locust (Schistocerca gregaria). Biochem J 245:365-370.

Isaac RE (1988) Neuropeptide-degrading endopeptidase activity in locust Schistocerca gregaria synaptic membrane. Biochem J 255:843848.

Jan LY, Jan YN (1982) Peptidergic transmission in sympathetic ganglia of the frog. J Physiol (Lond) 327:219-246.

Low MG, Saltiel AR (1988) Structural and functional roles of glycosylphosphatidylinositol in membranes. Science 239:268-275.

Marder E, Weimann JM (1992) Modulatory control of multiple task proccssing in the stomatogastric nervous system. In: Neurobiology of motor programme selection (Kien J, McCrohan C, Winlow B, eds), pp 3-19. New York: Pergamon.

Marder E, Hooper SL, Siwicki KK (1986) Modulatory action and distribution of the neuropeptide proctolin in the crustacean stomatogastric nervous system. J Comp Neurol 243:454-467.

Mayeri E, Rothman BS, Brownell PH, Branton WD, Padgett L (1985) Nonsynaptic characteristics of neurotransmission mediated by egglaying hormone in the abdominal ganglion of Aplysia. J Neurosci 5:2060-2077.

McDonald JK, Barrett AJ (1986) Mammalian proteases: a glossary and bibliography, Vol 2, Exopeptidases. San Diego: Academic.

McKelvy JF, Blumberg S (1986) Inactivation and metabolism of neuropeptides. Annu Rev Neurosci 9:415-434.

Molineaux CJ, Lasdun A, Michaud C, Orlowski M (1988) Endopeptidase 24.15 is the primary enzyme that degrades leutinizing hormone releasing hormone both in vitro and in vivo. J Neurochem 51:624633. 
Nusbaum MP, Marder E (1989a) A modulatory proctolin-containing neuron (MPN). I. Identification and characterization. J Neurosci 9:1591-1599.

Nusbaum MP, Marder E (1989b) A modulatory proctolin-containing neuron (MPN). II. State-dependent modulation of rhythmic motor activity. J Neurosci 9:1600-1607.

Nusbaum MP, Weimann JM, Golowasch J, Marder E (1992) Presynaptic control of modulatory fibers by their neural network targets. J Neurosci 12:2706-2714.

Owens DF, Menon JG, Rothman BS (1992) Structure-activity relationship of the neurotransmitter alpha-bag cell peptide on Aplysia LUQ neurons: implications regarding its inactivation in the extracellular space. J Neurobiol 23:656-670.

Polak JM, Bloom SR (1987) Regulatory peptides. Experientia 43:723850.

Quistad GB, Adams ME, Scarborough RM, Carney RL, Schooley DA (1984) Metabolism of proctolin, a pentapeptide neurotransmitter in insects. Life Sci 34:569-576.

Rose C, Camus A, Schwartz JC (1988) A serine peptidase responsible for the inactivation of endogenous cholecystokinin in brain. Proc Natl Acad Sci USA 85:8326-8330.

Schwarz TL, Lee GM-H, Siwicki KK, Standaert DG, Kravitz EA (1984) Proctolin in the lobster: The distribution, release, and chemical characterization of a likely neurohormone. J Neurosci 4:1300-1311.

Selverston AI, Moulins M (1987) The crustacean stomatogastric system. Berlin: Springer.

Sigvardt KA, Rothman BS, Brown RO, Mayeri E (1986) The bag cells of Aplysia as a multitransmitter system: identification of alpha bag cell peptide as a second neurotransmitter. J Neurosci 6:803-813.

Siwicki KK, Bishop CA (1986) Mapping of proctolin-like immunoreactivity in the nervous systems of lobster and crayfish. J Comp Neurol 243:435-453.

Sossin WS, Fisher JM, Scheller RH (1989) Cellular and molecular biology of neuropeptide processing and packaging. Neuron 2:14071417.

Squire CR, Talebian M, Menon JG, Dekruyff S, Lee TD, Shively JE,
Rothman BS (1991) Leucine aminopeptidase-like activity in Aplysia hemolymph rapidly degrades biologically active $\alpha$-bag cell peptide fragments. J Biol Chem 266:22355-22363.

Starratt AN, Brown BE (1979) Analogs of the insect myotropic peptide proctolin: synthesis and structure-activity studies. Biochem Biophys Res Commun 90:1125-1130.

Steele RW, Starratt AN (1985) In vitro inactivation of the insect neuropeptide proctolin in haemolymph from Periplaneta americana. Insect Biochem 15:511-519.

Sullivan MJ, Harding JW, Wright JW (1988) Differential effects of aminopeptidase inhibitors on angiotensin-induced pressor responses. Brain Res 456:249-253.

Thorsett ED, Wyvratt MJ (1987) Inhibition of zinc peptidases that hydrolyse neuropeptides. In: Neuropeptides and their peptidases (Turner AJ, ed), pp 229-292. Chichester: Horwood.

Turner AJ (1987) Endopeptidase-24.11 and neuropeptide metabolism. In: Neuropeptides and their peptidases (Turner AJ, ed), pp 183201. Chichester: Horwood.

Turner AJ, Matsas R, Kenny AJ (1985) Are there neuropeptide-specific peptidases? Biochem Pharmacol 34:1347-1356.

Turner AJ, Hooper NM, Kenny AJ (1989) Neuropeptide-degrading enzymes. In: Neuropeptides: a methodology (Fink G, Harmar AJ, eds), pp 189-223. New York: Wiley.

Umezawa $H$, Aoyagi $T$ (1983) Trends in research of low molecular weight protease inhibitors of microbial origin. In: Proteinase inhibitors: medical and biological aspects (Katunuma N, Umezawa $\mathbf{H}$, Holzer H, eds), pp 3-15. New York: Springer.

Weimann JM (1992) Multiple task processing in neural networks: numerous central pattern generators in the stomatogastric nervous system of the crab, Cancer borealis. PhD thesis, Brandeis University.

Weimann JM, Marder E, Evans B, Calabrese RL (1993) The effects of SDRNFLRFamide and TNRNFLRFamide on the motor patterns of the stomatogastric ganglion of the crab Cancer borealis. J Exp Biol 181:1-26.

White JD, Stewart KD, Krause KE, McKelvy JF (1985) Biochemistry of peptide-secreting neurons. Physiol Rev 65:553-606. 